\title{
Treatment Outcomes and Predictors of Recovery from Severe Acute Malnutrition Among Children Aged 6-59 Months Attending an Outpatient Therapeutic Program in Wenago District, Southern Ethiopia
}

This article was published in the following Dove Press journal: Nutrition and Dietary Supplements

\section{Yilkal Simachew iD ${ }^{\prime}$ \\ Taddese Zerfu ${ }^{2}$ \\ Wagaye Alemu (D) ${ }^{3}$ \\ 'School of Public Health, College of Medicine and Health Science, Hawassa University, Hawassa, Ethiopia; ${ }^{2}$ Department of Nutrition, College of Medicine and Health Science, Dilla University, Dilla, Ethiopia; ${ }^{3}$ Department of Public Health, College of Medicine and Health Science, Dilla University, Dilla, Ethiopia}

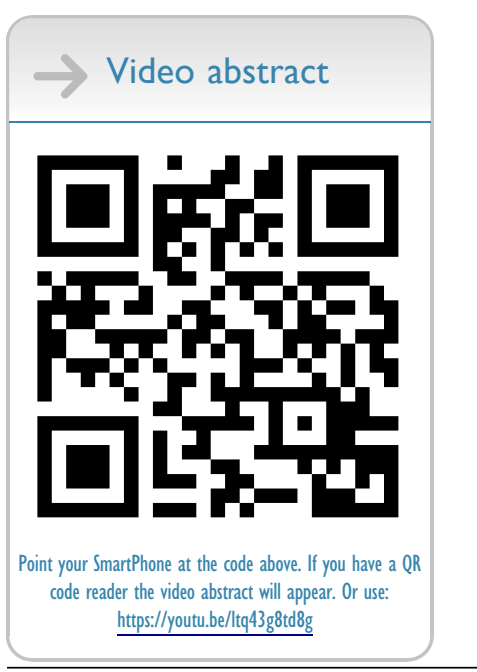

Correspondence: Yilkal Simachew School of Public Health, College of Medicine and Health Science, Hawassa University, P.O. Box: 1560, Hawassa, Ethiopia

Tel +25 I 941050775

$\mathrm{Fax}+251462122122$

Email joemakalister 123@gmail.com
Background: The outpatient therapeutic program (OTP) of children with severe acute malnutrition (SAM) brought the treatment approach closer to the community. In spite of the high coverage and accessibility, a low recovery rate of OTP is often reported. Thus, the aim of this study was to assess the treatment outcomes and identify predictors of recovery among children aged 6-59 months with SAM enrolled to OTP in Wenago district, Southern Ethiopia.

Methods: A facility-based cross-sectional study was conducted by assessing health records and interviewing mothers of 554 children, who were treated between July 2017 and February 2018. A single stage cluster sampling was used to enroll the study participants. The data were coded and entered into EpiData version 3.1, and analyzed by SPSS version 20. Binary logistic regression was used to identify predictors of recovery. All statistical tests in this study were declared significant at $P<0.05$.

Results: The recovery, average weight gain rate and length of stay were $70.4 \%, 3.9 \mathrm{~g} / \mathrm{kg} / \mathrm{day}$ and 6.67 weeks, respectively. The adjusted odds ratios to recovery of children who were treated with amoxicillin, born from a mother whose age at first marriage was $>18$ years, from a food secured household and had access to safe water sources were (AOR=3.97, 2.75, 3.21 and 2.96; 95\% $\mathrm{CI}=2.32,6.78,1.54,4.93,1.86,5.52$, and 1.61, 5.45), respectively. Conversely, children from households with three under-5 year olds had a $86 \%$ (AOR=0.14; $95 \%$ CI $0.05,0.38$ ) less risk of recovery as compared to children from households with only one under-5-year-old child.

Conclusion: The recovery rate, average daily weight gain and length of stay in the program were not within the acceptable sphere standards. Provision of amoxicillin, numbers of under5-year-old children in the house, maternal age at first marriage, a source of water and food security status were independently associated with recovery from SAM under OTP.

Keywords: outpatient therapeutic program, treatment outcome, severe acute malnutrition, Wenago district

\section{Introduction}

Malnutrition is more than a lack of food, it is a combination of factors: insufficient protein, energy and micronutrients, frequent infections or disease, poor care and feeding practices, inadequate health services, and poor water and sanitation. ${ }^{1}$ It 
encompasses both overnutrition associated with overweight and obesity, and undernutrition. It remains as the leading common cause of morbidity and mortality among children throughout the world. ${ }^{2}$ Undernutrition encompasses different nutritional disorders, including severe acute malnutrition (wasting and bilateral pitting edema), stunting, underweight, and micronutrient deficiency disorder. $^{3}$

According to the World Health Organization (WHO) definition, severe acute malnutrition (SAM) is a weight for height ratio (WFH) of less than -3 standard deviations (SD) below the median reference population or weight for height ratio of below $70 \%$ or presence of nutritional edema. ${ }^{4}$ Children suffering from SAM have a 5-20 times greater risk of death than well-nourished children. ${ }^{5}$

In 2016, nearly (7.7\%) 52 million of the world's under5-years-old children had acute malnutrition, and 17 million had SAM. ${ }^{6}$ More than two thirds of all acutely malnourished under-5-years-old children live in Asia and more than one quarter lives in Africa. Ethiopia is one of the countries with the highest under-5 child mortality rate, with malnutrition underlying to $51 \%$ of all children's deaths. $^{7}$ The 2016 Ethiopian Demographic and Health Survey (EDHS) reported 10\% of children 6-59 months of age are wasted (acute malnutrition). It has been estimated that approximately $3 \%$ of these children have SAM. According to Southern Nations Nationalities and Peoples' Region (SNNPR) 2016 annual report the incidence rate of SAM was 14 SAM cases per 1000 under-5 children and the Gedeo zone ranked the highest with 32 SAM cases per 1000 under-5 population. In a similar report, the incidence rate of SAM in the study area (Wenago district) was 48 SAM cases per 1,000 under-5 population. ${ }^{8}$

Previously, children with SAM were managed in a health facility through inpatient care. ${ }^{9}$ However this approach posed many challenges to effective treatment for both health systems and patients, some of the challenges were low coverage and impact, costliness, heavy staff work load, overcrowding, cross infections, and high mortality rate. ${ }^{5}$ To reduce those limitations, community-based management of acute malnutrition (CMAM) was endorsed with a joint statement of WHO and UNICEF in 2007. ${ }^{4}$ This advance decentralized management system to the community-based approach. Community outreach, outpatient management of SAM children without medical complications (OTP), inpatient management of SAM children with medical complications and the program addressing moderate acute malnutrition (MAM) were designed as components of CMAM.
The OTP offers service to severely malnourished children age 6-59 months. The admission criterion for OTP according to the protocol for management of SAM is Mid Upper Arm Circumference (MUAC) of less than $110 \mathrm{~mm}$ or WFH of less than $70 \%$ or presence of bilateral pitting edema. Only children who have appetite with Plumpy'Nut ${ }^{\circledR}$ and those who do not have medical complications are eligible for the OTP. ${ }^{9}$ This group of children represents over $90 \%$ of all SAM cases. ${ }^{10}$

However, children presenting with medical complications will not be admitted to OTP, rather they are referred to the therapeutic feeding unit (TFU). The TFU is provided in health centers and hospitals to manage severely malnourished children with medical complications as inpatients until their illness is stabilized. ${ }^{4,9}$

The OTP is provided by health extension workers at the health posts. The service is provided daily for new cases and one OTP day in a week is scheduled for follow up of enrolled cases. The children undergo an appetite test and receive ready to use therapeutic feeding (RUTF) and routine medications (Vitamin A, folic acid, antibiotics, deworming) for admission at home. They return weekly to the outpatient care site until they are discharged. ${ }^{9}$

Children admitted to OTP are discharged by their respective admission criteria. Children admitted with wasting get discharged from the OTP when they gain 15\% of weight at admission. Unlike wasting, children admitted with edema are discharged from the OTP after their edema has disappeared for 2 consecutive weeks., ${ }^{3,9}$ The treatment outcomes (recovery, death, default, weight gain, and length of stay) compared with international sphere standard to evaluate the program effectiveness. ${ }^{9}$ The reference values have been developed by sphere project and they give an indication of what might be considered acceptable and alarming (Table 1$)^{4}$

Good treatment outcome under OTP has social, psychological, cultural and economic implications. ${ }^{11}$ Despite this fact previous studies have concentrated on the factors that are associated with treatment outcomes like socio-demographic and anthropometric characteristics of children, medicalrelated factors, adherence to treatment protocol, comorbidity at admission and during follow up. However other equally important factors like maternal/caregiverrelated factors, household and environmental factors have been given little attention. ${ }^{12}$ In addition, even though Wenago district has a large number of children with SAM and admission to OTP, there is no published study conducted to show the program performance and factors associated with 
Table I The Sphere Standard Reference Value for the Main Indicators of OTP

\begin{tabular}{|l|l|l|}
\hline Performance Indicators & Acceptable & Alarming \\
\hline Recovery rate & $>75 \%$ & $<50 \%$ \\
Death rate & $<10 \%$ & $>15 \%$ \\
Default rate & $<15 \%$ & $>25 \%$ \\
Weight gain & $\geq 8 \mathrm{~g} / \mathrm{kg} /$ day & $<8 \mathrm{~g} / \mathrm{kg} /$ day \\
Length of stay & $<4$ weeks & $>6$ weeks \\
\hline
\end{tabular}

recovery. Therefore, this study aimed to measure the treatment outcomes and identify factors associated with recovery among SAM children aged 6-59 months that were admitted to OTP in Wenago district, Southern Ethiopia.

\section{Materials and Methods}

\section{Study Setting and Period}

The study was conducted in Wenago district Gedeo zone SNNP region, which is located $377 \mathrm{~km}$ from Addis Ababa (the capital city of Ethiopia), $102 \mathrm{~km}$ from Hawassa (Regional city) and $14 \mathrm{~km}$ from Dilla (capital of Gedeo zone) at ( $6^{\circ} 20^{\prime}$ and $\mathrm{E} 38^{\circ} 19^{\prime}$ ). The district is one of the most densely populated areas in the country. ${ }^{13}$ The district has 21 kebeles ( 4 urban and 17 rural kebele) and a total of 26 health facilities ( 6 health centers and 20 health posts), where only health posts provide OTP service. The common health problems in this district are malaria, diarrhea, under-5 pneumonia and malnutrition. ${ }^{8}$

The study was conducted between March 10 and May 20, 2018.

\section{Study Design}

A facility-based cross-sectional study was conducted.

\section{Source and Study Population}

All 6-59 months of age child-mothers/caregivers pairs, who were treated in the OTP at health facilities of Wenago district, were the source population.

All 6-59 months of age child-mothers/caregivers pairs with SAM who were treated in the selected OTP sites between July 1, 2017 and February 30, 2018 in Wenago district, were the study population.

\section{Inclusion and Exclusion Criteria}

All 6-59 months of age child-mother/caretaker pairs admitted to OTP between July 1, 2017 and February 30, 2018, and permanent residents of the Wenago district (who had lived there for at least 6 months) were included.
Children who transferred from the inpatient therapeutic care, children who were known to be suffering from other known chronic illnesses (TB, HIV/AIDS) and children with incomplete records on anthropometric measurements (weight, MUAC), socio-demographic data (age, gender), admission criteria and treatment outcome were excluded from the study in order to make clear comparisons and proper interpretations of the result.

\section{Sample Size Determination and Sampling Procedure \\ Sample Size}

Sample Size Determination for Treatment Outcome of OTP

The minimum sample size required for treatment outcome of OTP was calculated by using a single population proportion formula, using the following assumptions

$$
\mathrm{n}=(\mathrm{Z} \alpha / 2)^{2} * \mathrm{P}(1-\mathrm{P}) / \mathrm{d}^{2}
$$

$\mathrm{n}=$ minimum sample size

$$
(\mathrm{Z} \alpha / 2)=\text { Zvaluefor95\%confidencelevel }=1.96
$$

$\mathrm{P}=$ the recovery rate of children treated under OTP $67.7 \%$ taken from a study conducted in Kamba district, South west Ethiopia. ${ }^{14}$

$d=$ margin of error to be tolerated $(5 \%)$

$$
=(1.96)^{2}(0.677)(1-0.323) /(0.05)^{2}=336
$$

By considering $10 \%$ non response rate, and multiplying by 1.5 design effect the final sample size becomes 554 .

\section{Sample Size Determination for Factors Associated with Recovery}

The sample size determination for the second objective, that is identifying factors associated with recovery in OTP, wascalculated based on a double population proportion formula by using Epi info version 7 stat calc programs (Table 2).

Since the calculated sample size for the second objective was less than the sample size calculated for the first objective, 554 was taken as the final sample.

\section{Sampling Procedure}

Wenago district has a total of six health centers and 20 health posts, with only health posts providing OTP services. Homogeneity among the 20 health posts was assumed in terms of staff, use of same protocol for management, with all staffs taking training on SAM management. In addition population around health posts assumed nearly homogeneous. With 
Table 2 Sample Size Determination for Factors Associated with Recovery

\begin{tabular}{|l|l|l|l|l|l|l|l|l|}
\hline No & Factors & CI & Power & AOR & $\begin{array}{l}\text { Outcome in Un- } \\
\text { xposed (\%) }\end{array}$ & $\begin{array}{l}\text { Sample } \\
\text { Size }\end{array}$ & $\begin{array}{l}\text { Missing/Incomplete } \\
\text { Data }\end{array}$ & $\begin{array}{l}\text { Design } \\
\text { Effect }\end{array}$ \\
\hline Size
\end{tabular}

this assumption, 10 health posts were selected randomly. From the selected health posts, eligible children with SAM were identified from OTP cards for those admitted from July 1, 2017 to February 30, 2018. After this, whether the mother/ caregiver of an eligible child was a permanent resident of Wenago district was checked and a sampling frame was prepared for each OTP site. Finally, from the selected health posts a total of 554 eligible study subjects (child and mother pairs) were identified. The selection of the eligible study subjects is shown in Figure 1.

\section{Study Variables}

The "dependent variable" was the treatment outcome from OTP (recovered/not recovered).

The "independent variables" included the sociodemographic and admission characteristics of each child (age, sex, breast-feeding during treatment, referral system, admission status), the clinical characteristics of the children on admission (type of nutritional diagnosis, provision of routine medication at admission, co-morbidities on admission, appetite test on admission), the socio-demographic and

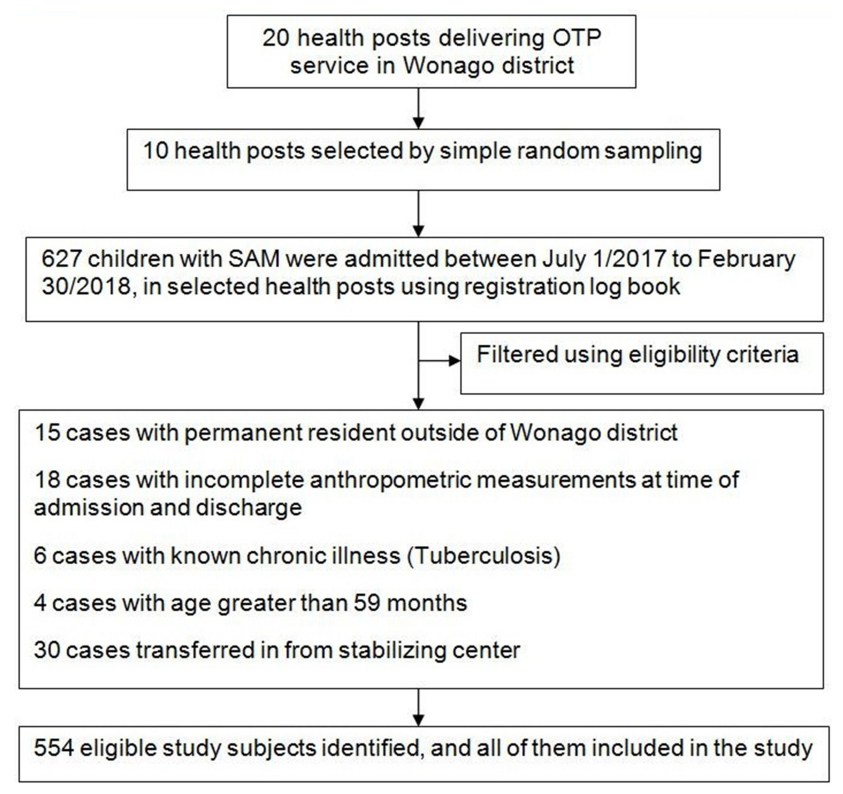

Figure I Schematic presentation of sampling procedure. economic characteristics of mothers/caregivers of the children (maternal age, maternal education, residence, marital status, mother's occupation, family size, number of under-5 children in the house, maternal age at first marriage, wealth index, maternal perception about child feeding, and distance of health institution from the residence), and environmentaland sanitation-related factors (source of water, water storage, availability of latrine, method of waste disposal, household food security status).

\section{Operational Definitions}

The "treatment outcome" was defined as recovered or not recovered from SAM management at OTP in this study.

"Recovered" was defined as a gain of $15 \%$ of weight at admission for wasting children and resolution of edema for 2 consecutive weeks for kwashiorkor children, ${ }^{9}$ while "not recovered" was defined as children discharged from OTP with outcome other than recovery in this study (death, default, non-responder, medical transfer and falsely recovered). ${ }^{15}$

"Non-responder" was defined as a patient that failed to reach the discharge criteria after 8 weeks of treatment in the program. ${ }^{9}$

A "defaulter" was defined as a child who was absent for two consecutive follow-up visits from the OTP and confirmed by home visit. 9

"Weight gain" is the average weight gain (in grams) for every $\mathrm{kg}$ of body weight of the child per day. Weight gain calculation was conducted for recovered children in the marasmus categories, with a formula of

$=($ Discharge weight in gram - Admission weight in gram)/ (Admission weight in $\mathrm{kg}$ )/ (Number of days in program). ${ }^{9}$

The "average length of stay" was calculated by adding the total number of days that each child stays in the OTP until cured, and dividing this by the number of children cured for a specific month. ${ }^{9}$

\section{Maternal Perception of Child Feeding}

Maternal perception about child feeding was assessed using Likert scale questions. At the end, mothers who 
scored above mean on all questions were labeled as having a positive perception about child feeding and those scoring below the mean were labeled as having a negative perception.

\section{Household Food Security Status}

Household food security status was labeled as a food secured household if the respondents replied no to all eight standard questions of the household insecure experience scale survey tool (HHFIES), and a food insecure household if the respondent's replied yes to at least one question. ${ }^{16}$

\section{Data Collection Procedure and Tool}

The data were collected using two approaches, review of the child OTP card (using a structured data abstraction form which were adopted from the Federal Minister of Health) ${ }^{9}$ and a structured interviewer administered questionnaire to collect data from mothers/caregivers of selected children.

The OTP card includes information like the sociodemographic characteristics of a child, including age, sex, patient baseline information, including date of admission, type of admission, admission anthropometry, and routine admission medication; follow up information on weight, MUAC, edema, appetite test, treatment outcome, and date outcome were ascertained. Baseline admission characteristics in terms of medications received and breast feeding. All these data were collected using the structured data abstraction forms. While maternal- and environmental-related factors of identifying children were collected using the structured questionnaire, after tracing mothers/caregivers of the identified children at their home. Data were collected using 10 diploma nurses and supervised by two supervisors with a bachelor degree in public health.

\section{Data Analysis}

The collected data were entered into EpiData software version 3.1 and exported to statistical package for social science (SPSS) version 20 for analysis. First, descriptive analysis was carried out for each of the variables. The association between dependent and independent variables was assessed and its strength presented using odd ratios and $95 \%$ confidence interval. Using binary logistic regression the crude relationship between each predictor variables and outcome variable was assessed, and those independent variables with a $P$-value less than 0.25 was considered as a candidate variable for multivariate logistic regression. Finally, a $P$-value less than 0.05 was declared statistically significant.

\section{Data Quality Control}

The questionnaire was first prepared in English then translated into Gedeofa and back translatedinto English by independent translators to check its consistency. Consensus on the compatibility of forward and backward translation was assured before the actual data collection activities.

Data collectors and supervisors were trained for 2 days by the principal investigator before the actual study commenced on the objectives of the study, how to extract data from the OTP card, how to interview, how to fill in the questionnaire and how to handle the questions asked by the study subjects. As part of the training, the data collection tool was pre-tested in $5 \%$ of the sample size at Dilla zuria wereda (adjacent to the study area) before the actual data collection time to check a data extraction form, address the study variables, as well to check the extent at which the questions were understood by the interviewee and to identify areas for modification and correction. Based on the pretest some chronological arrangements were made and two questions were also added to the questionnaire. The principal investigator and supervisors checked the completeness and consistency of collecting data on a daily basis and necessary feedback was given to the data collectors.

Before data entry, in order to make data processing easier, a code was given to each interviewer, and data entry format was prepared in EpiData software according to a pre-coded questionnaire. To reduce some errors during data entry, a check file was developed (to detect and refuse some data entry mistakes). Before conducting analysis in SPSS software, data cleaning was done to check for the presence of outliers, to check for consistency and to verify the skip pattern was followed. In addition, exploratory data analysis was carried out to check the levels of missing values and the presence of multi co-linearity.

\section{Ethical Considerations}

A letter of ethical clearance was obtained from Dilla University, College of Medicine and Health Science institution review board; which was then submitted to Gedeo zone health department. After having a formal letter of permission from Gedeo zone health department, the letter was submitted to Wenago district health office, and then a cooperation letter was obtained to collect data from 
selected health posts. After detailed explanation of the main purpose of the study, a written consent form (using their fingerprint) was obtained from mothers/caregivers of children to agree to the collection of data from them. The finger print consent process was approved by the Dilla University institutional Review board and this study was done in accordance with the declaration of Helsinki.

\section{Results}

The study included records of 554 children who had been managed for severe acute malnutrition under 10 selected OTP sites from July 1, 2017 to February 30, 2018, and their caregivers, which give $100 \%$ response rate.

\section{Socio-Demographic and Admission Characteristics of the Children}

Among the children included in the study, a majority or $291(52.5 \%)$ were females by gender and under 2 years $(323,58.3 \%)$ by age category. The median age of children at admission was 24 months with an inter quartile range of 12 to 36 months. A sizable proportion of the children (205, $37 \%$ ) were referred to OTP from the community health day (CHD) activities, followed by community volunteers 194 (35\%), and self referral 155 (28\%).

The health records of children whose data was assessed showed more than nine in ten $(92.4 \%)$ of children were new admissions, while the rest $(6.3 \%)$ and $(1.3 \%)$ being readmissions and return after default, respectively. Most (482, $87 \%)$ of the children were admitted from rural areas taking a median time of 30 minutes' walk to reach the health facility (Table 3).

\section{Clinical Characteristics of Children Admitted to OTP}

Three-quarters $(420,75.8 \%)$ of the children were admitted with wasting and the rest $(134,24.2 \%)$ with the presence of edema. Among the children who were admitted for presence of edema, more than three-quarters or 102 (76.3\%) had grade I edema, followed by 29 (21.6\%) had grade II edema, and 3 (2.2\%) had grade III edema.

On admission more than half $(309,55.8 \%)$ of the children were on breast feeding. Amoxicillin (376, $67.9 \%)$ and vitamin-A $(114,20.6 \%)$ were the most often supplied medication; while folic acid was the least supplied $(0.2 \%)$. All of the $554(100 \%)$ children admitted passed the appetite test and $457(96.4 \%)$ had a normal body temperature; but close to one in five $102(18.4 \%)$ had fast breathing (Table 4).

\section{Socio-Demographic and Economic Characteristics of Mothers/Caregivers of Selected Children}

The finding shows the median age of mothers/caregivers of children was 28 years with IQR of 25 to 31 years. The majority $(529,95.5 \%)$ of the participants were affiliated to the protestant faith. Mothers/caretakers from Gedeo ethnic group numbered 520 (93.9\%) of them. Close to three quarters or $409(73.8 \%)$ were illiterate.

Considering maternal family characteristics, more than three-quarters $(421,76 \%)$ of them were housewives and $519(93.7 \%)$ were married. The median family size of the household was 5 (with IQR of 4.7-6.0). More than half of the households had at-least two or more under-5 children; 259 (46.8\%) had two and 72 (13\%) had three under-5 children. In the same way, slightly above half, $290(52.3 \%)$ of the mothers/caregivers were married after 18 years of age, with a median age of 18 (IQR 16-19 years). Two-thirds $(66.1 \%)$ of mothers had a positive perception toward appropriate child feeding practices. Socioeconomic status of the study population was

Table 3 Socio-Demographic and Admission Characteristics of Children Admitted to OTP from Severe Acute Malnutrition in Wenago District, Southern Ethiopia 2018

\begin{tabular}{|l|l|}
\hline Variables & Frequency (\%), N=554 \\
\hline $\begin{array}{l}\text { Sex } \\
\text { Male }\end{array}$ & $263(47.5)$ \\
Female & $291(52.5)$ \\
\hline $\begin{array}{l}\text { Age of children at admission } \\
\leq 24 \text { months } \\
>24 \text { months }\end{array}$ & $323(58.3)$ \\
\hline $\begin{array}{l}\text { Referred by } \\
\text { Community volunteers }\end{array}$ & $231(41.7)$ \\
\hline $\begin{array}{l}\text { Self referred } \\
\text { From CHD }\end{array}$ & $194(35)$ \\
\hline $\begin{array}{l}\text { Admission status } \\
\text { New } \\
\text { Return after default } \\
\text { Re admission }\end{array}$ & $155(28)$ \\
\hline Distance in minutes & $205(37)$ \\
$\leq 24$ & $512(92.4)$ \\
$\geq 25$ & $7(1.3)$ \\
\hline
\end{tabular}

Note: ${ }^{\text {c}}$ community health day. 
Table 4 Clinical Characteristics of Children on Admission Under OTP from Severe Acute Malnutrition in Wenago District, Southern Ethiopia 2018

\begin{tabular}{|l|l|}
\hline Clinical Characteristics & Frequency (\%), N=554 \\
\hline $\begin{array}{l}\text { Type of nutritional diagnosis } \\
\text { Wasting }\end{array}$ & $420(75.8)$ \\
Edema & $134(24.2)$ \\
\hline $\begin{array}{l}\text { Breast feeding } \\
\text { Yes }\end{array}$ & $309(55.8)$ \\
No & $245(44.2)$ \\
\hline Amoxicillin provision & \\
Yes & $376(67.9)$ \\
\hline No & $178(32.1)$ \\
Yes & \\
No & $114(20.6)$ \\
\hline De-worming & $440(79.4)$ \\
\hline $\begin{array}{l}\text { Yes } \\
\text { No }\end{array}$ & $88(15.9)$ \\
Not applicable & $386(69.7)$ \\
\hline Folic acid & $80(14.4)$ \\
Yes & $102(18.4)$ \\
\hline No & $1(0.2)$ \\
\hline Fast & $553(99.1)$ \\
\hline
\end{tabular}

assessed by wealth index and one-third (184, 33.2\%) of the participants belonged to low socioeconomic status (Table 5).

\section{Environmental- and Sanitation-Related Characteristics}

The study shows almost all $(530,95.7 \%)$ of the participants had private latrines, but only $117(22 \%)$ had a hand washing facility with the latrine. Similarly, more than three-quarters $(417,75.3 \%)$ had access to an improved water source, and $228(41.2 \%)$ reported to treat drinking water before consumption. More than two-thirds (386, $69.7 \%$ ) stored drinking water in plastic "jerricans" and the rest stored it in traditional clay pots. In addition, more than two-thirds $(370,66.8 \%)$ of respondents reported disposing of solid waste in the open field. More than half or $289(52.2 \%)$ of the participant households were food secured, while the remaining 265 (47.8\%) households were food insecure (Table 6).
Table 5 Socio-Demographic and Economic Characteristics of Mothers/Caregivers of Children in Outpatient Therapeutic Feeding Program in Wenago District, Southern Ethiopia 2018

\begin{tabular}{|c|c|}
\hline Variables & $\begin{array}{l}\text { Frequency }(\%) \\
\mathrm{N}=554\end{array}$ \\
\hline \multicolumn{2}{|l|}{ Religion } \\
\hline Protestant & $529(95.5)$ \\
\hline Orthodox & $24(4.3)$ \\
\hline Muslim & $\mathrm{I}(0.2)$ \\
\hline \multicolumn{2}{|l|}{ Ethnicity } \\
\hline Gedeo & $520(93.9)$ \\
\hline Oromo & $23(4.2)$ \\
\hline Amhara & $8(1.4)$ \\
\hline Gurage & $3(0.5)$ \\
\hline \multicolumn{2}{|l|}{ Mothers' education } \\
\hline Illiterate & $409(73.8)$ \\
\hline Read and write & $90(16.2)$ \\
\hline Primary (grade I-8) & $42(7.6)$ \\
\hline Secondary (grade 9-12) \& above & $13(2.4)$ \\
\hline \multicolumn{2}{|l|}{ Mothers' occupation } \\
\hline Housewife & $421(76)$ \\
\hline Merchant & $62(11.2)$ \\
\hline Farmer & $41(7.4)$ \\
\hline Daily labors & $30(5.4)$ \\
\hline \multicolumn{2}{|l|}{ Wealth index } \\
\hline Low & $184(33.2)$ \\
\hline Middle & $177(32)$ \\
\hline High & $193(34.8)$ \\
\hline \multicolumn{2}{|l|}{$\begin{array}{l}\text { Maternal perception on child } \\
\text { feeding }\end{array}$} \\
\hline Negative & $188(33.9)$ \\
\hline Positive & $366(66.1)$ \\
\hline
\end{tabular}

\section{Treatment Outcomes}

Of the total 554 children admitted to an outpatient therapeutic program, the recovery rate from severe acute malnutrition was 390 (70.4\%) (Figure 2). The median recovery time from OTP was 7 weeks with IQR of 6-8 weeks. Half (195, 50\%) of the children recovered from SAM at less than 7 weeks of duration. Among the wasting children who recovered from SAM had gained an average weight of $3.9 \mathrm{~g} / \mathrm{kg} / \mathrm{day}$.

\section{Predictors of Recovery Among Children Admitted to OTP}

During the initial bivariate analysis, referral system, distance, diagnosis at admission, provision of antibiotics, provision of vitamin-A, residence, maternal educational status, family size, number of under-5 children in the house, 
Table 6 Environmental- and Sanitation-Related Characteristics of the Participants of Outpatient Therapeutic Feeding Program in Wenago District, Southern Ethiopia 2018

\begin{tabular}{|l|l|}
\hline $\begin{array}{l}\text { Environmental- and Sanitation-Related } \\
\text { Characteristics }\end{array}$ & $\begin{array}{l}\text { Frequency (\%), } \\
\mathbf{N}=\mathbf{5 5 4}\end{array}$ \\
\hline $\begin{array}{l}\text { Have latrine } \\
\text { Yes }\end{array}$ & $530(95.7)$ \\
No & $24(4.3)$ \\
\hline $\begin{array}{l}\text { Hand washing facility with the latrine } \\
\text { Yes }\end{array}$ & $117(22)$ \\
No & $413(78)$ \\
\hline $\begin{array}{l}\text { The source of drinking water } \\
\text { Improved water source } \\
\text { Unimproved water source }\end{array}$ & $417(75.3)$ \\
\hline Solid waste disposal means & $137(24.7)$ \\
Open field & \\
Disposal pit & $370(66.8)$ \\
Composite & $19(3.4)$ \\
Burning & $110(19.9)$ \\
\hline Household food security status & $55(9.9)$ \\
\hline $\begin{array}{l}\text { Food secure } \\
\text { Food insecure }\end{array}$ & $289(52.2)$ \\
\hline
\end{tabular}

maternal age at first marriage, source of water, maternal perception on child feeding, wealth index, and household food security status had significant associations with recovery at $0.25 P$-value (Table 7 ).

But, applying the multivariate logistic regression: administration of antibiotics, the number of under-5 children in the house, maternal age at first marriage, a source of water, and household food security status remain in the

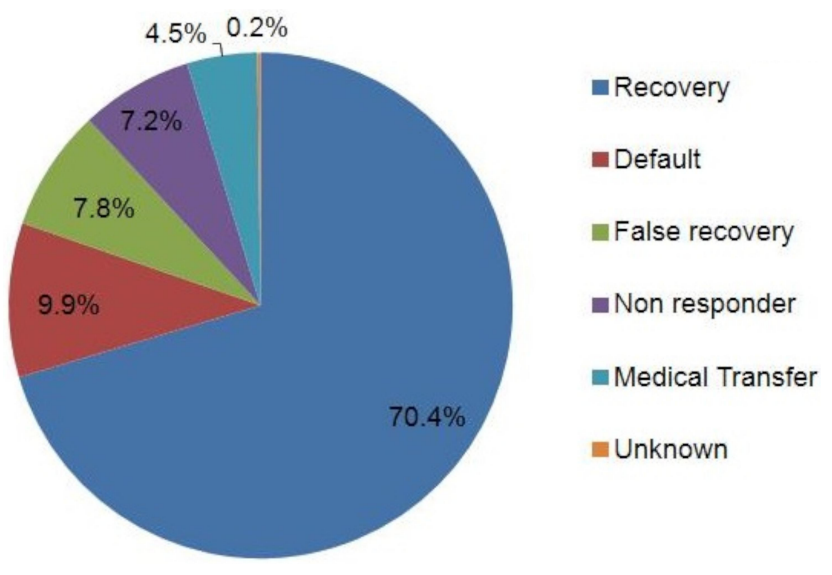

Figure 2 The treatment outcome of SAM children admitted to outpatient therapeutic program, Wenago district, Southern Ethiopia 2018. final model predicting outcome of recovery from OTP at $0.05 P$-value. Children provided with amoxicillin were 3.97 times more likely to recover from SAM than to those who were not given amoxicillin ( $\mathrm{AOR}=3.97$ at 95\% CI: 2.32, 6.78). Children from households which had three under-5 children had $86 \%$ reduced odds of recovery as compared to children from households which had only one under-5 child ( $\mathrm{AOR}=0.14$ at $95 \% \mathrm{CI}$ : 0.05 , 0.38 ). The odds of recovery from OTP among children born from mothers whose age at first marriage was 18 years and above was 2.75 times higher than that of children born from mothers whose age at first marriage was below 18 years (AOR=2.75 at 95\% CI: 1.54, 4.93). Children from households that had an improved water source for consumption had 2.96 times higher probability of recovery from SAM as compared to children from households that used unimproved water sources $(\mathrm{AOR}=2.96$ at $95 \% \mathrm{CI}: 1.61,5.45)$. Families living in food secured households had a 3.21 times higher chance of their children recovering from SAM as compared to those families living in food insecure households ( $\mathrm{AOR}=3.21$ at 95\% CI: 1.86, 5.52) (Table 7).

\section{Discussion}

\section{Treatment Outcomes}

The findings of this study revealed 390 (70.4\%) SAM children admitted to OTP recovered. This indicates the recovery rate was lower than the international sphere standard which set the lower threshold at $75 \% .{ }^{17}$ This finding is lower than findings from studies carried out in Shebedino district, southern Ethiopia $(78.7 \%)^{18}$ and Bedawacho district with a recovery rate of $85 \%{ }^{19}$ This disparity might be because, in this study a child discharged as recovered without reaching discharge criteria was labeled as false recovery, while the above two studies did not assess false recovery. The low recovery rate may be explained by inadequate provision of routine medications and interrupted provision of RUTF.

In contrast, the recovery rate is higher than the study done in Tigray region with a recovery rate of $61.7 \%$ and Sidama zone with a recovery rate of $68.8 \%{ }^{11,20}$ This may be explained by the presence of a high default rate of $13.8 \%$ and $24.1 \%$ in the Tigray and Sidama studies, respectively.

The default rate of $55(9.9 \%)$ is within the acceptable range of sphere standard $(<15 \%) .{ }^{17}$ The low default rate may indicate that the mothers/caregivers in the study area were aware about the consequence of defaulting from 
Table 7 Bivariate and Multivariate Analysis of Factors Associated with Recovery Among Children Aged 6-59 Months with Severe Acute Malnutrition Admitted to OTP at Wenago District, Southern Ethiopia 2018

\begin{tabular}{|c|c|c|c|c|}
\hline \multirow[t]{2}{*}{ Variables } & \multicolumn{2}{|c|}{ Treatment Outcome } & \multirow[t]{2}{*}{ COR $(95 \% \mathrm{Cl})$} & \multirow[t]{2}{*}{ AOR $(95 \% \mathrm{Cl})$} \\
\hline & Recovered & Not Recovered & & \\
\hline \multicolumn{5}{|l|}{ Referral system } \\
\hline Community volunteer & 128 & 66 & 1 & 1 \\
\hline Self referred & 137 & 18 & $3.92(2.21,6.96)^{*}$ & $\mathrm{I} .76(0.8 \mathrm{I}, 3.8 \mathrm{I})$ \\
\hline CHD & 125 & 80 & $0.80(0.53,1.21)$ & $0.61(0.33,1.10)$ \\
\hline \multicolumn{5}{|l|}{ Distance } \\
\hline$\leq 24$ & 126 & 22 & $3.08(1.87,5.06)^{*}$ & $\mathrm{I} .2 \mathrm{I}(0.6 \mathrm{I}, 2.4 \mathrm{I})$ \\
\hline$\geq 25$ & 264 & 142 & 1 & 1 \\
\hline \multicolumn{5}{|l|}{ Diagnosis } \\
\hline Wasting & 284 & 136 & $0.55(0.34,0.87)^{*}$ & $0.89(0.44,1.83)$ \\
\hline Edema & 106 & 28 & I & 1 \\
\hline \multicolumn{5}{|l|}{ Amoxicillin provision } \\
\hline Yes & 307 & 69 & $5.09(3.43,7.54)^{*}$ & $3.97(2.32,6.78)$ \\
\hline No & 83 & 95 & 1 & 1 \\
\hline \multicolumn{5}{|l|}{ Vitamin-A } \\
\hline Yes & 93 & 21 & $2.13(1.27,3.56)^{*}$ & $1.32(0.65,2.68)$ \\
\hline No & 297 & 143 & 1 & 1 \\
\hline \multicolumn{5}{|l|}{ Residence } \\
\hline Urban & 61 & 11 & I & 1 \\
\hline Rural & 329 & 153 & $0.38(0.19,0.75)^{*}$ & $0.67(0.25,1.73)$ \\
\hline \multicolumn{5}{|l|}{ Maternal education } \\
\hline No formal education & 337 & 160 & I & 1 \\
\hline Formal education & 53 & 4 & $6.29(2.23,17.68)^{*}$ & $1.23(0.37,4.12)$ \\
\hline \multicolumn{5}{|l|}{ Family size } \\
\hline$I-5$ & 241 & 82 & $1.61(1.11,2.33)^{*}$ & $0.78(0.43,1.42)$ \\
\hline$\geq 6$ & 149 & 82 & I & 1 \\
\hline \multicolumn{5}{|c|}{ Number of under-5 children } \\
\hline I & 194 & 29 & 1 & 1 \\
\hline 2 & 182 & 77 & $0.35(0.22,0.56)^{*}$ & $0.67(0.36,1.25)$ \\
\hline 3 & 14 & 58 & $0.03(0.01,0.07)^{*}$ & $0.14(0.05,0.38)$ \\
\hline \multicolumn{5}{|l|}{ Age at first marriage } \\
\hline$<18$ & 128 & 136 & I & 1 \\
\hline$\geq 18$ & 262 & 28 & $9.94(6.28,15.7)^{*}$ & $2.75(1.54,4.93)$ \\
\hline \multicolumn{5}{|l|}{ Source of water } \\
\hline Improved & 337 & 80 & $6.67(4.38,10.17)^{*}$ & $2.96(1.61,5.45)$ \\
\hline Unimproved & 53 & 84 & I & 1 \\
\hline \multicolumn{5}{|l|}{ Treat drinking water } \\
\hline Yes & 202 & 26 & $5.70(3.58,9.06)^{*}$ & $1.76(0.98,3.18)$ \\
\hline No & 188 & 138 & I & 1 \\
\hline \multicolumn{5}{|c|}{ Maternal perception on child feeding } \\
\hline Negative & 112 & 76 & I & 1 \\
\hline Positive & 278 & 88 & $2.14(1.47,3.12)^{*}$ & $1.67(0.96,2.89)$ \\
\hline
\end{tabular}


Table 7 (Continued).

\begin{tabular}{|c|c|c|c|c|}
\hline \multirow[t]{2}{*}{ Variables } & \multicolumn{2}{|c|}{ Treatment Outcome } & \multirow[t]{2}{*}{ COR $(95 \% \mathrm{Cl})$} & \multirow[t]{2}{*}{ AOR $(95 \% \mathrm{Cl})$} \\
\hline & Recovered & Not Recovered & & \\
\hline \multicolumn{5}{|l|}{ Household ood security status } \\
\hline Secured & 253 & 36 & $6.56(4.29,10.03)^{*}$ & $3.21(1.86,5.52)$ \\
\hline Insecure & 137 & 128 & I & I \\
\hline \multicolumn{5}{|l|}{ Wealth index } \\
\hline Low & 133 & 51 & I & I \\
\hline Middle & 100 & 77 & $0.49(0.32,0.77)^{*}$ & $0.68(0.36,1.27)$ \\
\hline High & 157 & 36 & $1.67(1.02,2.7 \mathrm{I})^{*}$ & $1.06(0.5 \mathrm{I}, 2.20)$ \\
\hline
\end{tabular}

Notes: $* P$-value less than 0.25 in the bivariate analysis, I indicates reference category, bold numbers are $P$-value $<0.05$ in the multivariate analysis. Abbreviation: $\mathrm{CHD}$, community health day.

OTP. The low default rate could also be linked with poor socioeconomic status of households, which force them to attend the OTP for plump nut in order to fulfill the basic needs of the household (to share with other under-5 children, or sell some of the RUTF to feed the whole family).

The average weight gain of children admitted with marasmus was $3.9 \mathrm{~g} / \mathrm{kg} / \mathrm{day}$, which is far out of the acceptable range of international sphere standard. ${ }^{16}$ The finding was lower as compared to a report from Kamba district $(5.76 \mathrm{~g} / \mathrm{kg} /$ day $)$ and Wolayita region $(4.2 \mathrm{~g} / \mathrm{kg} /$ day $) .{ }^{14,15}$ The lower average weight gain below sphere standard and the above two studies might be explained by inadequate provision of routine medications and improper utilizations of RUTF.

The average length of stay of children with SAM in OTP was 6.67 weeks. This result is far outside of the acceptable minimum sphere standard, which is 4 weeks. ${ }^{17}$ This finding is in line with studies done in Enderta district, northern Ethiopia (6.28 weeks). ${ }^{12}$ The average length of stay could be increased above the acceptable range because $7.2 \%$ of the recovered children were allowed to stay in the program for longer than 8 weeks. However, those children should have been referred for inpatient treatment in a stabilizing center at their 8th week of stay in OTP, when they fail to reach the discharge criteria. Inadequate or partial provision of routine medications and the intention of caregivers to stay in the program for long periods to secure a supply of RUTF might also contribute to the delay of recovery from SAM.

\section{Factors Associated with Recovery}

Children given amoxicillin were 3.97 times more likely to recover from SAM than those who were not given amoxicillin. The finding was in line with the reports from OTP in Kamba, Tigray and Kenya. ${ }^{11,14,21}$ This can be explained by the following reasons; almost all children with SAM experience bacterial overgrowth in small bowel, this enteric bacteria frequently are the source of systemic infection by translocation across the bowel wall. This results in malabsorption of nutrients, diarrhea and poor appetite. So, even if they do not have clinical signs of infection, they have to treat blindly. ${ }^{9}$ By suppressing the bacterial growth in the small bowel it facilitates the recovery progress of children from SAM in OTP.

Children from mothers whose age at first marriage was 18 years and above had a better chance of recovery as compared to those who were from mothers whose age at first marriage was under 18 years. This result was in line with a report in Tigray. ${ }^{12}$ The explanation for this could be because early marriage had a negative impact over maternal health outcome, and this situation increases the likelihood of poor infant and child outcome. ${ }^{22}$ In addition, early married women are usually forced to end their education early and this reduces their employment participation and gives them less power and decision making within the household. ${ }^{23}$ All of those factors will affect the child caring practice of the mother and this might affect the treatment outcome/recovery of children with SAM.

Children from households that use improved water sources had a higher chance of recovery as compared to children from households that use unimproved water sources. This finding agrees with the studies done in South Wollo zone of Amhara region and Tahoua region, Southern Niger, their reports indicating that having improved water sources is independently associated with improved program outcomes. ${ }^{24,25}$ This could be because an unprotected water source enhances a child's 
susceptibility to diarrheal and intestinal parasitic infection (hookworm), which in turn results in malabsorption of nutrients, poor appetite and anemia. Hence; a child who uses a protected water source is less vulnerable to diarrheal and intestinal parasitic infection, and hence more easily develops a high recovery rate as compared with a child using an unprotected water source.

Households with three under-5 children had an $86 \%$ reduced chance of recovery compared to households with only one under-5 child. It deduced that the birth spacing is one of the critical determinants of child recovery from SAM in OTP. This could be due to increased division of available resources in the household resulting in a nutritional shortfall and might force the presence of plump nut sharing among other healthy under- 5 children. Mothers' who have three children under 5-years of age may not properly take care of their children and also the household sanitation and hygienic conditions could be neglected while she is involved in income generating and reproductive works.

A family who lives in a food-secured household has a higher chance of having children recover from SAM as compared to their counterparts. Because SAM is a symptom of broader problems that affect a family rather than a disease in an individual. ${ }^{26}$ This can be explained because, even though RUTF provided as treatment for affected children, in food insecure households the actual amount of RUTF consumed by SAM children can be less than the amount provided due to sharing with other children in the household or use of RUTF as a commodity for meeting the household economies and food need, which endangers the child's recovery.

\section{Conclusion}

The findings of the study revealed that the recovery rate and the average weight gain were below sphere standard range, also the treatment duration (length of stay) was longer than the sphere recommendation. Factors like amoxicillin provision, maternal age at first marriage, a source of water, the number of under- 5 children in the house and food security status are predictors of recovery of SAM children in OTP. Therefore, stakeholders like the federal minister of health should consider integrating OTP with agricultural extension programs and productive safety net programs (PSNP) in food insecure areas to improve the recovery of SAM treatment. Wenago district health office needs to strengthen health education for all family members about the benefits of healthy birth spacing and use of family planning methods. Wenago district gender office needs to educate the community to avoid the harmful practice of early marriage. Health centers should focus on creating the capacity of HEW on proper managements of SAM. For researchers, a prospective study should be conducted for better information by including other factors not included under this study, such as the effects of anemia and proper provision of treatment to the index child at home.

\section{Abbreviations}

CHD, community health day; CMAM, community-based management of acute malnutrition; EDHS, Ethiopian Demographic and Health Survey; EFY, Ethiopian Feasible Year; GDP, gross domestic product; HDA, health developmental army; HEWs, health extension workers; IQR, inter quartile range; MAM, moderate acute malnutrition; MUAC, mid upper arm circumference; OR, odds ratio; OTP, outpatient therapeutic program; PSNP, productive safety net program; RUTF, ready to use therapeutic feeding; SAM, severe acute malnutrition; SNNPR, South Nation Nationality People Region; SPSS, Statistical Package for Social Science; TFU, therapeutic feeding unit; UNICEF, United Nations Children's Emergency Fund; WFH, weight for height; WHO, World Health Organization.

\section{Acknowledgments}

The authors would like to express their deepest acknowledgement to the NORAD project for their financial support to conduct this research. Furthermore, the authors would like to thank health extension workers of Wenago district for their full cooperation and vital assistance during data collection. Finally, the authors would like to thank all the data collectors, supervisors and research participants who took part in the study.

\section{Disclosure}

The authors report no conflicts of interest in this work.

\section{References}

1. UNICEF. Improving Child Nutrition: The Achievable Imperative for Global Progress. New York; 2013.

2. Victora CG. Causes of child deaths: looking to the future. Lancet. 2015;385(9966):398-399. doi:10.1016/S0140-6736(14)61695-0

3. WHO Guideline. Updates on the Management of Severe Acute Malnutrition in Infants and Children. Vol. 2013. Geneva: World Health Organization; 2013:6-54.

4. WHO, UNICEF. Community Based Management of Severe Acute Malnutrition. A Joint Statement by the World Health Organization, the World Food Programme, the United Nations System Standing Committee on Nutrition and UNICEF; 2007. 
5. Reed S, Kouam CE, Alebachew A, Fekadu HRM. Evaluation of Community Management of Acute Malnutrition (CMAM): Ethiopia Country Case Study. Evaluation Report. New York: UNICEF; 2012.

6. UNICEF, WHO, World Bank Group. Level and Trends in Child Malnutrition; 2017.

7. Got FDRE. National Nutrition Programme June 2013-June 2015. Addis Ababa: Government of Federal Democratic Republic of Ethiopia; 2013.

8. SNNPR health bureau. Public Health Emergency Management, Annual Report; 2016.

9. Golden MGY. Protocol for the Management of Severe Acute Malnutrition. Ethiopia: MOH; 2007.

10. International Federation of Red Cross and Red Crescent Societies (IFRC). World Disasters Report: Focuson Hunger and Malnutrition; 2011.

11. Yebyo HG, Kendall C, Nigusse DLW, Lemma W. Outpatient therapeutic feeding program outcomes and determinants in treatment of severe acute malnutrition in Tigray, Northern Ethiopia: a retrospective cohort study. PLoS One. 2013;8(6):2-10. doi:10.1371/journal.pone.0065840

12. Massa D, Woldemichael K, Tsehayneh B, Tesfay A. Treatment outcome of severe acute malnutrition and determinants of survival in Northern Ethiopia: a prospective cohort study. Int J Nutr Metab. 2016;8(April):12-23.

13. Southern Nation Nationalities and People' Region State Bureau of Finance and Economic Development, Annual Statistical Abstract; 2012.

14. Shanka NA, Lemma SAD. Recovery rate and determinants in treatment of children with severe acute malnutrition using outpatient therapeutic feeding program in Kamba District, South West Ethiopia. J Nutr Disord Ther. 2015;5(2). doi:10.4172/21610509.1000155

15. Kabalo MY, Seifu CN. Treatment outcomes of severe acute malnutrition in children treated within outpatient therapeutic program (OTP) at Wolaita Zone, Southern Ethiopia: retrospective cross-sectional study. J Heal Popul Nutr. 2017;36(1)1-8.
16. FAO. Methods for Estimating Comparable Prevalence Rates of Food Insecurity Experienced by Adults Throughout the World; 2016.

17. Charter H. Minimum Standards in Food Security and Nutrition. 3rd ed. Sphere hand book; 2011.

18. Mengesha MM, Deyessa N, Sileshi B, Dessie Y. Treatment outcome and factors affecting time to recovery in children with severe acute malnutrition treated at outpatient therapeutic care program. Glob Health Action. 2016;1:1-10.

19. Collins S, Sadler K. Outpatient care for severely malnourished children in emergency relief programs: a retrospective cohort study. Lancet. 2002;360(9348):1824-1830.

20. Yorra DT, Sagar GY. Survival rate and determinants in treatment of children with severe acute malnutrition using outpatient therapeutic feeding program in Sidama Zone, South Ethiopia. IOSR J Math. 2016;12(3):86-100.

21. Mbaya D, Bitok LK, Karani AK, Osano B, Habtu M. Outcomes of severely malnourished children aged 6-59 months on outpatient management program in Kitui County Hospital, Kenya. Open J Pediatrics. 2015;05(04):326-333. doi:10.4236/ojped.2015.54049

22. United Nations, WHO. Guildeline, on Maternal, Newborn, Child and Adolescent Health. The Partnership for Maternal, Newborn and Child Health. 2012.

23. International Planned Parenthood Federation in Collaboration with Forum on Marriage and the Rights of Women and Girls. Early Marriage and Poverty: Exploring Links for Policy and Programme Development; 2010.

24. Bizuneh A. Impacts of wash on community-managed acute child malnutrition in Ethiopia. 2010;(December).

25. Dorion C, Hunter PR, Van den Bergh R, et al. Does village water supply affect children's length of stay in a therapeutic feeding program in Niger? Lessons from a médecins sans frontières program. PLoS One. 2012;7(12):12. doi:10.1371/journal.pone.0050982

26. Tadesse E, Berhane Y, Hjern A, Olsson P, Ekstro E. Perceptions of usage and unintended consequences of provision of ready-to-use therapeutic food for management of severe acute child malnutrition. Southern Ethiopia. Health Policy Plan. 2015;1-8.
Nutrition and Dietary Supplements

\section{Publish your work in this journal}

Nutrition and Dietary. Supplements is an international, peerreviewed, open access journal focusing on research into nutritional requirements in health and disease, impact on metabolism and the identification and optimal use of dietary strategies and supplements necessary for normal growth and development. The journal welcomes submitted papers covering original research, basic science, clinical \& epidemiological studies, reviews and evaluations, guidelines, expert opinion and commentary, case reports and extended reports. The manuscript management system is completely online and includes a very quick and fair peer-review system, which is all easy to use. Visit http://www.dovepress.com/testimonials.php to read real quotes from published authors. 